\title{
Experimental Examination over heat Exchanging Capacity on the Hollow Pipe Incorporated with Corrugated Copper Plate Dividend and Baffles
}

\author{
Armstrong. M, Sivasubramanian. M
}

\begin{abstract}
Heat exchanging devices produce an outstanding part in numerous engineering applications. Because of this, a varied sort of researches are undertaking to decrease the size and cost of the heat transfer equipment with high performance by indulging in diverse invaluable works similar to changing its design, incorporating corrugated structures with different dimension with different flow configurations. In this work, the design of double pipe heat exchanger had been modified similar to the plate type model with the incorporation of a corrugated copper plate which separates the hot and cold fluid inside the SS304 material tube. Three baffles at the top and two baffles at the bottom of the plate have been placed to reduce the velocity and heat interaction timing of the fluids. This could enhance the surface area of the plate and point of contact between the plate surface and fluid particle flowing over the plate surface. The experiment had been undergone with the parameters like engendering the flow arrangements of hot and cold fluid in counter current direction, hot fluid in the three sided baffle at the top and cold fluid at the two sided baffle at the bottom. This allowed liquids of differing thermodynamic equilibrium to interact, bringing about thermal transfer to calculate its maximum efficiency. In addition to these factors, the heat exchanging performance has been estimated with the heat transfer coefficient using LMTD method gave $8-10 \%$ enhancement in the overall heat transfer coefficient with respect to the mass flow rate.
\end{abstract}

Keywords-Heat Exchanger design, Corrugated Copper plate, SS304 Pipe, Heat transfer coefficient

\section{INTRODUCTION}

Heat exchanging devices are performing an extraordinary role in many domestic and industrial applications to exchange energy from one system to the other system due to the temperature difference. Due to the shortage in energy due transferring equipment is very much essential nowadays, so the researchers are working in various aspects to attain an efficient heat exchanging device. Currently, heat transfer in the systems is maximized by introducing dynamic innovative design to suit for the respective industrial process depending on its thermodynamic properties. The enhancement in the heat transfer had been achieved by augment the surface area of the separator which divides the hot and cold fluid by

Revised Manuscript Received on December 30, 2019.

* M. Armstrong

Armstrong M*, Mechanical Engineering, Kalasalingam Academy of Research and Education, Krishnankovil, India. Email: Armstrong@klu.ac.in

Sivasubramanian. M, Automobile Engineering, Kalasalingam Academy of Research and Education, Krishnankovil, India Email: m.sivasubramaniana@klu.ac.in to over population around the world, highly efficient heat

enhancing the efficiency and minimizing the resistance to fluid flow with optimum material cost. Rafał Andrzejczyk et al (1) experimentally performed a comparison between the normal tube in tube with the tube in tube with wire insert, plain U- tube bend and U-bend with turbulator. In this, the numerical validation had been done with the NTU method which concludes that the exchangers with wire inserts gave up to $280 \%$ heat transfer enhancement and $85 \%$ higher heat transfer rate. The authors also focused on the $U$ bend design and annulus heat transfer performance compared to the tube side heat transfer rate. Wei Wang et al (2) studied the new design of the double pipe heat exchanger incorporated with the corrugated inner tube structure. The author predicted with CFD analysis of the tube also which gave a wide improvement due to the increased surface area and which had given high performance in heat transfer rate also. So the research in finding new design of the heat exchanger is widely undergoing by many researchers. Antonio C. Caputo et al (3) discussed the optimization in the software tools in the industrial heat exchangers using genetic algorithms to predict its capability of producing a less expensive heat exchanger design. The author had mainly focused on the software tools of the shell and tube heat exchanger in varied processing industries and came in to an enhanced software tool using genetic algorithms. Kamel Milani Shirvan et al (4) focused on the introduction of porous media in the double pipe heat exchanger and studied the numerical simulation and sensitivity study of the turbulent flow arrangements with Darcy-Brinkman-Forchheimer and the k-epsilon turbulent models. The authors found that mean Nusselt number enhances with the increment in the Reynolds number and with decrement in the Darcy number and porous substrate thickness. The sensitivity analysis showed that at $\operatorname{Re}=5000$, substrate thickness $=1 / 3$ and Darcy number $=10^{-5}$. Xue Chen et al (5) introduced the foam material as an inner tube for heat exchanging process. In that, the thermal radiation between the hot and cold fluid increases the thermal exchange. Decreased porosity, increased pore density and increased exchanger length increases the heat effectiveness. Seyed Shahab Mozafarie et al (6) reported that the thermal characteristic of a non-newtonian fluid was studied with the CFD analysis. The authors concluded that the use of helical fin enhanced the rotational flow and which further enhanced by the increment of fin pitch. In this work the new design had been implemented in the double pipe heat exchanger by introducing a corrugated plate as a separator in a tube with baffle arrangements over it. 


\section{Experimental Examination over heat Exchanging Capacity on the Hollow Pipe Incorporated with Corrugated Copper Plate Dividend and Baffles}

This gave a good thermal characteristics and high heat transfer rate with varied mass flow rate.

\section{PROBLEM IDENTIFICATION}

The main problem had been identified by researchers are the need of high efficient heat exchanger which exchanges the heat at less time interval. Industries are finding difficulty to increase the rate of heat transfer in the heat exchanger and so many researchers are working on it to enhance its performance.

- It was observed that enhancement factor increases by decreasing the fin spacing (hydraulic diameter) of the flow channel at the same value of volume concentration and coolant flow rate.

- The contact between the surface and fluid have less time to transfer heat.

- All researchers are trying to solve the energy crisis all over the universe by improving heat transfer performance and to produce an efficient heat exchanger at reduced cost.

- There was a reduction in the heat exchange between many heat exchanging pipe materials. Hence there is a need of higher heat exchange pipe material for the loss in the energy exchange this would enhance the efficiency of a particular applications.

- So this work bounce a shot to fabricate a new heat exchanger with cost effectively to enhance the heat transfer using extended surface and hollow pipe by reducing the problems which had been discussed above.

\section{DESIGN OF THE HEAT EXCHANGER}

The heat exchanger had been designed with the length of $50 \mathrm{~cm}$ and annulus diameter of $6 \mathrm{~cm}$. The corrugated plate is made of copper which separates the hot and cold fluid. This acted as convection medium for transferring the heat due to the temperature difference.
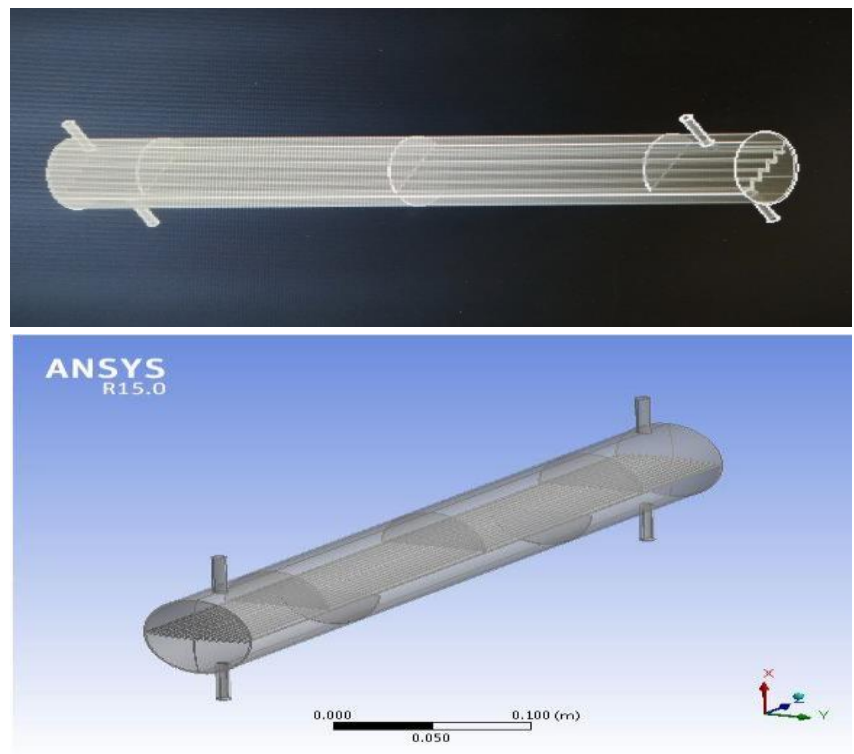

Fig. 1. 3 D Design of the heat exchanger
The baffles are separated in both sides to slow down the fluid and to have a greater contact time between the two fluids over the corrugated plate. Each baffle plates are placed $12.5 \mathrm{~cm}$ gap in hot fluid side and $20 \mathrm{~cm}$ gap in cold side. The outer annulus had been made of SS304 steel pipe which is used in many industrial and domestic applications as a heat exchanging tubes.

\section{EXPERIMENTAL SETUP AND PROCEDURE}

In this work, the design of double pipe heat exchanger had been modified similar to the plate type model with the incorporation of a corrugated copper plate which separates the hot and cold fluid inside the SS304 material tube, the hot fluid (water) is obtained from an electric geyser and it flows through one side of the corrugated copper plate by maintaining in a steady state through hot water tank. The cold fluid is also water obtained from cold water tank and it flows through the another opening of the steel pipe to the opposite side of the corrugated copper plate attached in a steel pipe, enabling the heat exchanger to run as a counter flow apparatus. This can be done by operating the different valves provided. Temperature of the fluids can be measured using thermocouples. Flow rate is measured and controlled using a rotameter for both hot and cold side. In this, the forced convection through for the heat transfer between the two different temperature moving streams with varied velocity. This upheld the temperature difference between the two fluids. Here, the hot fluid produced is moved over a corrugated copper plate in one side and cold fluid in the other side through the baffles fitted in the both sides made a quick transferring energy from hot side to cold side in a particular mass flow rate enhances the performance of this model. These temperature difference is maintained till the steady state is maintained with particular mass flow rate. The new temperature gradient for hot and cold fluid will be observed once the inlet and outlet mass flow rate and new set of readings could be obtained to measure the difference in the rate of heat transfer and heat transfer coefficient.

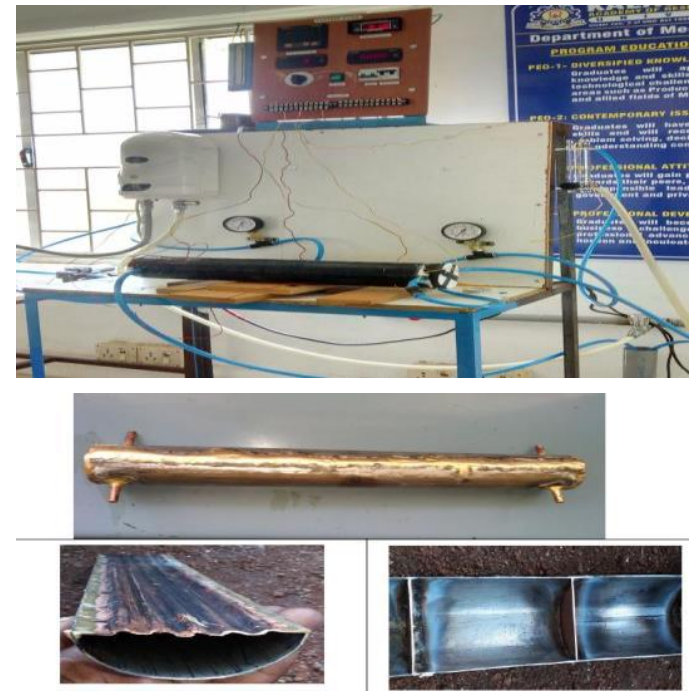

Fig. 2. Experimental Setup 
In reality, the temperatures will never be completely stable. So, the thermostat had been placed in the hot water tank to control the inlet temperature and it could maintain the hot water temperature as constant while flowing inside the heat exchanger. This would helpful to make the system in a steady state condition. At different mass flow rate, all the readings were measure and the overall heat transfer coefficient were found.

\section{RESULTS AND DISCUSSION}

The readings were taken by maintaining the hot water inlet and cold water inlet temperature as constant with respect to the different mass flow rates. In this, the heat transfer coefficient of water in the hot and cold water side increases with respect to the increase in the mass flow rate of hot and cold water. This enhances the overall heat transfer coefficient of the system which increases with respect to the mass flow rate. It indicates the performance of this new model heat exchanger is performing same as like that of other model heat exchangers.

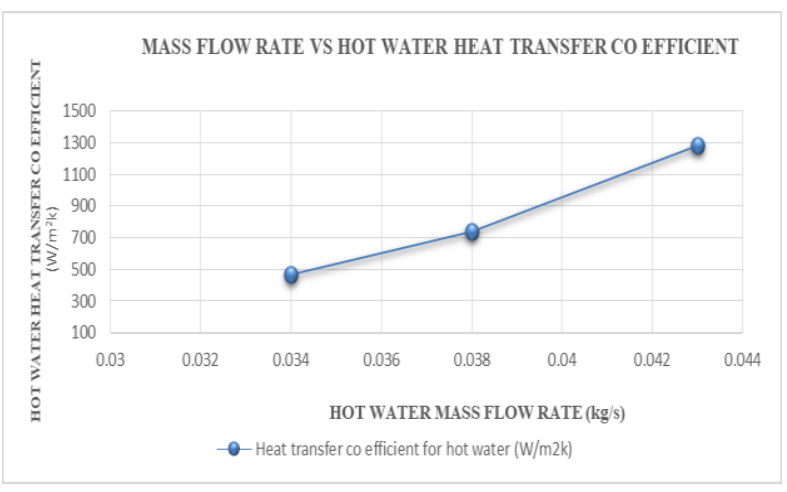

Fig. 3. Mass flow rate of hot water vs Hot water heat transfer coefficient

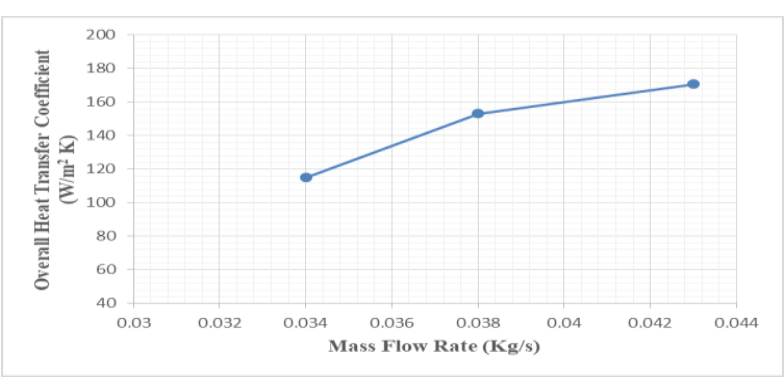

Fig. 4. Mass flow rate vs over all heat transfer coefficient

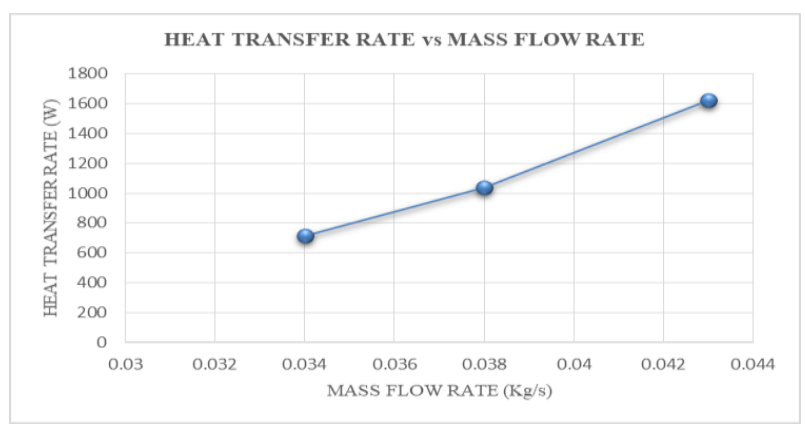

Fig. 5. Heat transfer rate vs Mass flow rate
But as per the calculated readings, the overall heat transfer coefficient and heat transfer rate gradually increases with respect to the increase in mass flow rate of the fluid. This depicts this model is performing and exchanging heat like typical heat exchanging phenomenon.

\section{CONCLUSION}

Here, from this experimental study, the heat exchanger is designed, fabricated and experimentation had been done with various mass flow rates. The design and fabrication had been done with the normal SS304 material steel tube as an annulus part and corrugated copper plate as a separator inside the steel tube. This model might reduce the cost of the heat exchanger with high grade materials like copper, since two tubes are required to fabricate the tube in tube heat exchanger. But in this, one high thermal conductivity copper plate and low cost outer steel pipe had been utilized to fabricate the pipe. The observation with different mass flow rate with the constant hot water temperature of $50^{\circ} \mathrm{C}$ is done in counter current flow of fluids in the pipe and the results revealed that if the mass flow rate of hot water increases, the heat transfer coefficient also increases like a normal heat exchangers, the effectiveness decreases with respect to the increase in mass flow rate. Thus the performance of the heat exchanger is doing well as similar to the normal tube in tube heat exchanger with $8-10 \%$ enhancement in the overall heat transfer coefficient. This could be identified that this heat exchanger have an ability to transfer with high performance comparatively to the other tube in tube heat exchangers. The outer tube with SS304 had high resistance to heat transfer with less thermal conductivity which resist the heat travel to the atmosphere and also its price is very less comparative to other SS material with higher properties. These types of low cost high performing heat exchangers are needed to enhance the rate of heat transfer and it would play a major role in reduction in the energy crisis due to lack of fossil fuels.

\section{REFERENCES}

1. Rafał Andrzejczyk, Tomasz Muszynski, Przemyslaw Kozak,' Experimental investigation of heat transfer enhancement in straight and Ubend double-pipe heat exchanger with wire insert", Chemical Engineering \& Processing: Process Intensification 136 (2019) 177-190.

2. Wei Wang, Yaning Zhang, Kwan-Soo Lee, Bingxi Li “Optimal design of a double pipe heat exchanger based on the outward helically corrugated tube", International Journal of Heat and Mass Transfer 135 (2019) 706-716

3. Antonio C. Caputo, Pacifico M. Pelagagge, Paolo Salini 'Heat Exchanger Optimized Design Compared With Installed Industria Solutions', Applied Thermal Engineering (2015), Vol 87, pg.371-380.

4. Kamel Milani Shirvan, Rahmat Ellahi, Soroush Mirzakhanlari, Mojtaba Mamourian.," Enhancement of Heat Transfer and Heat Exchanger Effectiveness in a Double Pipe Heat Exchanger Filled with Porous Media: Numerical Simulation and Sensitivity Analysis of Turbulent Fluid Flow", Applied Thermal Engineering (2016)

5. Xue Chen, Chuang Sun, Xinlin Xia, Rongqiang Liu , Fuqiang Wang," Conjugated heat transfer analysis of a foam filled double-pipe heat exchanger for high-temperature application", International Journal of Heat and Mass Transfer 134 (2019) 1003-1013. 


\section{Experimental Examination over heat Exchanging Capacity on the Hollow Pipe Incorporated with Corrugated Copper Plate Dividend and Baffles}

6. Seyed Shahab Mozafarie, Kourosh JavaherdehAmine Allouhi,“ Numerical design and heat transfer analysis of a non-Newtonian fluid flow for annulus with helical fins", Engineering Science and Technology, an International Journal xxx (2019) xxx

7. Cheng-Hung Huang 'The Design of Uniform Tube Flow Rates for ZType Compact Parallel Flow Heat Exchangers', Chun-Hsien Wang International Journal of Heat and Mass Transfer, (2013) Vol 57, pg.608-622.

8. D. Han, W.F. He, F.Z. Asif 'Experimental Study of Heat Transfer Enhancement Using Nanofluid In Double Tube Heat Exchanger', (2017) Vol 142, pg.2547-2553.

9. Hebert Lugo-Granados, Martín PicónNúñez 'Modelling Scaling Growth in Heat Transfer Surfaces and Its Application on the Design of Heat Exchangers', Energy (2018), Volume 160, 1 October 2018, Pages 845-854

10. Muhammad Saeed, Man-Hoe Kim 'Heat Transfer Enhancemen Using Nanofluids (A12O3-H2O) In Mini Channel Heat Sinks', International Journal of Heat and Mass Transfer, (2018),Vol 120, pg.671-682.

11. N. Piroozfam, A. Hosseinpour Shafaghi 'Numerical Investigation of Three Methods for Improving Heat Transfer In Counter-Flow Heat Exchangers', S.E. Razavi International Journal of Thermal Sciences, (2018) Vol 133, pg.230-239.

12. Olga Arsenyeva, Julian Tran, Mark Piper, Eugeny Kenig 'An Approach for Pillow Plate Heat Exchangers Design for Single-Phase Applications', Applied Thermal Engineering, (2018).

13. Robert J. Kee, Berkeley B. Almand, Justin M. Blasi, Benjamin L. Rosen, Marco Hartmann, Neal P. Sullivan, Huayang Zhu 'The Design, Fabrication, and Evaluation of A Ceramic Counter-Flow Micro Channel Heat Exchanger', Applied Thermal Engineering, (2011) Vol 31

14. Sandip K. Saha, Martine Baelmans 'A Design Method for Rectangular Micro Channel Counter- Flow Heat Exchangers, International Journal of Heat and Mass Transfer, (2014) Vol 74, pg.1-12.

15. Somei Hayashia, Kitipat Siemanonda 'Compact and Multi-Stream Heat Exchanger Design', Computer Aided Chemical engineering, (2018) Vol 43, pg.663-668

16. Kexin Xu, Robin Smith, Nan Zhang'Design and Optimization of Plate Heat Exchanger Networks' Computer Aided Chemical Engineeirng, (2018)Volume 40, 2017, Pages 1819-1824

17. Rajendran Senthilkumar, Sethuramalingam Prabhu, Marimuthu Cheralathan Experimental, 'Investigation on Carbon Nano Tubes Coated Brass Rectangular Extended Surfaces', Applied Thermal Engineering, (2013), Vol 50.

18. Mohammad Hadi, Haj Mohammad, Mohammad Reza, Hassani Ahangar, Mohammad Hemmat Esfe, Ali Alirezaie, 'Price- Performance Evaluation of Thermal Conductivity Enhancement of Nanofluids with Different Particle Sizes', Applied Thermal Engineering, (2017).

19. Muhammad Mahmood, Aslam Bhutta, Nasir Hayat, Muhammad Hassan Bash, Ahmer Rais Khan, Kanwar Naveed Ahmad, Sarfaraz Khan, 'CFD applications in various heat exchangers design', Applied Thermal Engineering, (2012), Vol 32, pg. 1-12.

20. Kamel Milani Shirvan, Rahmat Ellahi, Soroush Mirzakhanlari, Mojtaba Mamourian, 'Enhancement of Heat Transfer and Heat Exchanger Effectiveness in a Double Pipe Heat Exchanger Filled with Porous Media: Numerical Simulation and Sensitivity Analysis of Turbulent Fluid Flow', Applied Thermal Engineering, (2016)

21. Anas El Maakoul, Azzeddine Laknizi, Said Saadeddine, Abdellatif Ben Abdellah, Mohamed Meziane, Mustapha El Metoui (2017) 'Numerical design and investigation of heat transfer enhancement and performance for an annulus with continuous helical baffles in a double-pipe heat exchanger', Energy Conversion, (2017), Vol 133, pg. $76-86$.

22. Saud Ghani, Seifelislam Mahmoud Ahmad Gamaledin, Mohammed Mohammed Rashwan, Muataz Ali Atieh 'Experimental Investigation of Double-Pipe Heat Exchangers in Air Conditioning Applications Experimental Investigation of Double-Pipe Heat Exchangers in Air Conditioning Applications.

23. John M. Gorman, Kevin R. Krautbauer, Ephraim M. Sparrow 'Thermal and Fluid Flow First-Principles Numerical Design of an Enhanced Double Pipe Heat Exchanger, Applied Thermal Engineering, 2015

24. Zhan Liu, Yanzhong $\mathrm{Li}$, Ke Zhou, 'Thermal analysis of double-pipe heat exchanger in thermodynamic vent System', Energy Conversion and Management, (2016), Vol 126, pg. 837-849.
25. Mohamad Omidi, Mousa Farhadi, Mohamad Jafari, 'A comprehensive review on double pipe heat exchangers', Applied Thermal Engineering, (2017), Vol 110, pg. 1075-1090.

26. X.Y. Sun, Y.J. Dai, T.S. Ge, Y. Zhao, R.Z. Wang ,Comparison of performance characteristics of desiccant coated airwater heat exchanger with conventional air-water heat exchanger experimental and analytical investigation, (2017).

27. Prabhata K. Swamee, Nitin Aggarwal, Vijay Aggarwal, 'Optimum design of double pipe heat exchanger', Heat and Mass Transfer, (2008), Vol 51, pg. 2260-2266. 